\title{
«Por el orden de Celso»: aspectos de la influencia del De medicina en la cirugía europea del Renacimiento
}

\section{Pedro Conde Parrado}

Doctor en Filología Clásica. Profesor Titular de Filología Latina. Universidad de Valladolid. pedro@fyl.uva.es

Dynamis

[0211-9536] 2008; 28: 217-241
Fecha de recepción: 16 de mayo de 2007

Fecha de aceptación: 15 de noviembre de 2007

SUMARIO: 1.-Introducción. 2.-La dignificación profesional del cirujano. 2.1.-La cirugía, antiquissima y evidentissima. 2.2.-El cirujano, médico completo. 3.-Las doctrinas de Celso en la cirugía del Renacimiento. 3.1.-Celso y la osteopatología: las lesiones craneales y la fractura apéchema. 3.2.-Celso y la cirugía «vulneraria»: las heridas mortales. 3.3.—Influencia de Celso en dos tipos de intervenciones quirúrgicas. 3.3.1.—La gangrena. 3.3.2.—El cálculo en la vejiga. 4.-Conclusiones.

RESUMEN: En el presente artículo estudiamos algunos de los aspectos más destacados de la recepción del De medicina de Cornelio Celso en la literatura y en la práctica quirúrgica del Renacimiento. Nuestro estudio se centra sobre todo en dos ámbitos: el socioprofesional, con la defensa por parte de los cirujanos de la dignidad de su disciplina, y el relativo a la recepción de las doctrinas celsianas más apreciadas en el siglo XVI.

PALABRAS CLAVE: Celso, De medicina, cirugía, Europa, Renacimiento, siglo XVI.

KEYWORDS: Celsus, De medicina, surgery, Europe, Renaissance, 16th century.

\section{Introducción $\left(^{*}\right)$}

El enciclopedista romano Cornelio Celso (siglo I dC) dedica el séptimo y octavo libros de su única obra conservada, el De medicina [en adelante, De med.], a dar cuenta de las intervenciones terapéuticas en las que «el médico no se topa con una herida, sino que la provoca él mismo [para curar,

(*) Artículo realizado en el ámbito del Proyecto de Investigación HUM2005-0285-FILO. 
se entiende]» y en las que el propio Celso considera que «mayor auxilio aporta la mano que el medicamento» ${ }^{1}$. Esas intervenciones las adscribe al dominio de la tercera de las partes en que, según él, se dividía la ciencia médica: la Chirurgia ${ }^{2}$. Por tanto, Celso no da cabida, como acción exclusivamente quirúrgica, a la «cura de muchas heridas y llagas» de las que se ocupaba en los tres últimos capítulos del libro quinto, a pesar de que «las reclaman como tarea propia los cirujanos». El criterio, pues, manejado por Celso para distinguir lo genuinamente quirúrgico de lo que puede ser sanado también por fármacos es la distinción entre 'heridas' provocadas con fin terapéutico por la misma persona que ha de curar y heridas previas a la intervención médica.

Trataremos de mostrar cómo se sustanció la gran influencia del De med. en el dominio de la cirugía renacentista, incluyendo la receptio de alguno de esos pasajes del libro quinto cuyo argumento continuaban «reivindicando» para sí los cirujanos de la época.

El estudio de esa influencia lo centraremos en dos planos: el socioprofesional, orientado a la defensa de la dignidad de la cirugía y sus prácticos, y el relativo a la recepción de las doctrinas celsianas más apreciadas en el siglo XVI.

\section{La dignificación profesional del cirujano}

Entre los diferentes profesionales del ejercicio médico en el siglo XVI, fueron los cirujanos quienes en mayor medida vieron puesta en entredicho la dignidad científica de su quehacer terapéutico. Su excesiva «vecindad» con el «empirismo» no académico de los llamados barberos-cirujanos o los sanadores ambulantes los hacía sospechosos de ejercer una técnica que no exigía gran esfuerzo intelectual, sino poco más que habilidad en las manos y aptitud para imitar a un maestro avezado.

A ello se añadía la índole misma de su objeto terapéutico: constituido este casi siempre por heridas, contusiones, luxaciones, etc., hacía innece-

\footnotetext{
1. De med., lib. VII, proemio, 5. Hemos consultado la edición de Mazzini, Innocenzo. A. Cornelio Celso. La chirurgia (Libri VII e VIII del De medicina). Macerata: Università; 1999. El proemio general al De med. In: Mudry, Philippe. La préface du De medicina de Celse, Ginebra-Berna: Institut Suisse de Rome; 1982.

2. De med., proemio, 9.
} 
sario recurrir a factores que eran imprescindibles para la «otra» medicina, tales como el conocimiento de las causas más o menos ocultas del mal o el régimen de vida previo al mismo ${ }^{3}$.

A ese carácter particular de sus objetivos terapéuticos se sumaba el de sus procedimientos, que exigían al cirujano trabajar en desagradable contacto con hemorragias o abscesos de pus y a practicar operaciones tan desagradables como la amputación de algún miembro. La definición de la cirugía ofrecida por Celso - quae manu curat - casi obligaba a que esta disciplina fuera mal vista en una época en que la exigencia de habilidad manual en el oficio desempeñado y la consideración social de éste eran inversamente proporcionales.

Por otra parte, los resultados de la intervención quirúrgica solían mostrarse de inmediato: ambigua ventaja si se tiene en cuenta que podía seguirse para su autor buena reputación si el resultado era feliz, o descrédito y fama de carnifex en caso de fracasar ${ }^{4}$.

Desde el lado de los médicos o físicos, los cirujanos universitarios coetáneos eran vistos, en general, como un extenso grupo profesional lindante por un extremo con el mundo de la medicina no académica antes mencionada (algebristas, batidores de cataratas, etc.) y, por otro, con su propio terreno de actuación terapéutica.

Ante esta situación, los cirujanos renacentistas se preocuparon tanto por vindicar la dignidad de su profesión frente a los «empíricos» iletrados como por reclamar la igualdad de rango de su disciplina con la cultivada por los médicos universitarios. En ello no hacían sino continuar con una reivindicación ya presente en los más ilustres cirujanos bajomedievales, representantes de la llamada «cirugía racional» (Teodorico Borgognoni,

3. A este respecto, véase Conde Parrado, Pedro. Hipócrates latino. El De medicina de Cornelio Celso en el Renacimiento. Valladolid: Universidad de Valladolid; 2003. p. 81-82; Nutton, Vivian. Humanist Surgery. In: Wear, Andrew; French, Roger K.; Lonie, Ian M., eds. The Medical Renaissance of the sixteenth century. Cambridge: Cambridge University Press; 1985. p. 75-99, 298-303. Sobre la cirugía española de la época, Fresquet Febrer, José Luis. La práctica médica en los textos quirúrgicos españoles en el siglo XVI. Dynamis. 2002; 22: 251-277.

4. Los cirujanos, por la propia índole de su oficio, eran muy sensibles a cuestiones de deontología, para no verse acusados de homicidio en caso de tratamientos fallidos con resultado de muerte. En De med. hay pasajes muy interesantes en este sentido, que gozaron de una amplia recepción en los textos médicos y no médicos del Renacimiento. Véase «El proemio al De medicina y la deontología celsiana» en Conde Parrado, n. 3, p. 73-118. 
Guglielmo da Saliceto, Lanfranco de Milán, Henri de Mondeville) ${ }^{5}$. Lo que ofrecía ahora el «reciente» De medicina celsiano era una amplia panoplia de nuevos y, al mismo tiempo y sobre todo, antiguos argumentos para sustentar esa defensa profesional.

En otro lugar, al estudiar la fortuna del proemio al De med. en el Renacimiento ${ }^{6}$, hemos señalado que, en asuntos de físicos, como las causas ocultas de las enfermedades, los cirujanos debían mantener una actitud, conciliadora hasta lo ambiguo, que no los hiciera parecer excesivamente preocupados por las disquisiciones cuasi-filosóficas de aquellos, inaceptables en el quehacer quirúrgico; pero tampoco podían dar la impresión de estar insuficientemente formados, como los «empíricos», en aspectos generales básicos para la medicina, tales como los de índole fisiológica (así, saber curar eficazmente un absceso, pero reconocer también el exceso de qué humor lo había provocado). Estos conocimientos solo podían adquirirse por la lectura (sobre todo, en las lenguas «universitarias» latín y griego, no se olvide) de las fuentes genuinas de la medicina antigua.

No tardaron en comprender, como bien ha observado Nutton ${ }^{7}$, que la vía más eficaz para lograr el éxito era conectar con la nueva corriente humanista que dominaba la medicina de la época; para ello, debían impregnarse de la sabiduría antigua en el ámbito tanto de la patología como de la anatomía quirúrgica, que algunos de los más significados representantes de ese movimiento intelectual estaban sacando a la luz. Pronto comprendieron que en ese saber clásico no era una obra menor el recién descubierto $D e$ med. de Celso ${ }^{8}$, del que leyeron con provecho sus pasajes de cirugía y al que convirtieron en un autor dilecto para esa disciplina. A este aspecto de la receptio celsiana dedicaremos la segunda parte del artículo.

Por otro lado, a la vez que iban logrando su admisión en el mundo de la «alta medicina», se vieron forzados a justificarlo poniendo de manifiesto

5. McVaugh, Michael. The Rational Surgery of the Middle Ages. Florencia: SISMEL-Edizioni del Galluzzo; 2006, especialmente el capítulo segundo, p. 53-87.

6. Conde Parrado, n. 3.

7. Nutton, n. 3.

8. Recordemos que el De med., «desaparecido» desde una época ignorada de la Antigüedad, permaneció oculto durante toda la Edad Media hasta que a comienzos del siglo XV (1426) fue redescubierto un manuscrito en Siena — poco después algunos más — que lo contenía. Su editio princeps en 1478 la significa como una de las obras médicas antiguas más tempranamente impresas. 
la prestancia de la cirugía dentro de la tripartición terapéutica heredada de Celso: es el segundo de los frentes a que se hacía referencia más arriba.

Es posible que en algunos casos obedeciera a exigencias retóricas en virtud de las cuales el proemio de una obra debía remarcar la primacía intelectual de la disciplina a que se dedicara; sin embargo, la insistencia en ello por parte de casi todos los tratados quirúrgicos en la época hace sospechar que, lejos de ser mero tópico, constituyera un ejercicio de afirmación profesional. Es en este punto donde debemos exponer cómo especialmente los proemios - el general y el del libro séptimo- elaborados por Celso supusieron el mayor legado de la medicina antigua a la cirugía renacentista para salir de su secular relegamiento socio-profesional.

\subsection{La cirugía, antiquissima $y$ evidentissima}

En el proemio general al De med. la única referencia de Celso a la cirugía se limita, aunque no es poco, a señalar que se trata, junto con la farmacia, de la disciplina médica más antigua, dado que los primeros médicos de que se tiene noticia - los hijos de Esculapio: Podalirio y Macaón- curaban «con hierro y medicamentos» las heridas de guerra, según Homero.

El proemio al libro séptimo se dedica ya por entero a la cirugía: se recuerda en primer lugar que es una de las tres partes de la medicina y que no excluye el empleo de las otras dos, «medicamentos y régimen de vida», si bien en ella es la acción «manual» la que proporciona mayores posibilidades de curación. A renglón seguido se la presenta como aquella cuyo efecto es evidentissimus frente a las otras dos; es decir, que a nadie le cabe duda de que los efectos inmediatamente observables tras su acción terapéutica se deben exclusivamente a ella, mientras que en la dietética es siempre posible una intervención de la fortuna (es la de efecto menos evidens), y con la farmacia no se logra indefectiblemente la curación, que puede sobrevenir sin que ella intervenga (es de efecto más evidens que la ratio victus, pero menos que la chirurgia). Continúa Celso señalando cómo es una disciplina que, aun siendo vetustissima, fue cultivada más por Hipócrates, «padre de toda la medicina», que por los médicos anteriores a él. Constituyen, por tanto, las nociones «muy antigua» y de efectos «más evidentes» los dos pilares sobre los que asienta Celso su proemio a los libros quirúrgicos y su visión de la cirugía en el contexto de la medicina. 
Como más arriba indicábamos, la aparición en los prefacios a los libros quirúrgicos del siglo XVI de una apología de la profesión del cirujano era un hecho casi indefectible; podemos afirmar que igualmente lo era la presencia de estas ideas celsianas que tan adecuadamente podían aducirse en unos textos pensados para dignificar el quehacer de esos profesionales.

Hemos escogido como guía expositiva la prefación con que inicia su obra el mejor especialista español del siglo y uno de los más cualificados de su tiempo, el vallisoletano Dionisio Daza Chacón (1510-1596); veremos cómo va insertando en ese texto, profusamente «autorizado», los pasajes referidos de Celso traducidos al castellano, y añadiremos para cada caso el testimonio de otros cirujanos de renombre.

La tripartición de la Medicina presente en el proemio celsiano es la segunda de las dos citas de autores antiguos con las que Daza abre su Pratica y Teorica de Cirugia en romance y en latín ${ }^{9}$, de 1580. Para sustentar que la cirugía es la parte más antigua de la medicina -objetivo de todo el primer capítulo - trae a colación una de las partes del proemio de Celso al séptimo libro que mayor satisfacción podía producir a estos cirujanos; aquella en la que se señala nada menos que al padre de toda la medicina como perfeccionador de la propia cirugía, nacida mucho tiempo antes:

«Esto confirmó Cornelio Celso, cuando dijo (hablando de la cirugía): Esta parte de la medicina, como sea antiquísima, mucho mas la afiló y la puso en punto Hipócrates, padre de la medicina, que todos los que antes de él la trataron, en lo cual da entender que mucho antes de Hipócrates se había inventado» ${ }^{10}$.

En este mismo capítulo Daza alega a Celso como uno de los testimonios para apoyar su idea de que la medicina había nacido de la experiencia - lo que no deja de ser significativo en un cirujano-, menciona la figura de Esculapio y sus hijos, Podalirio y Macaón, que presenta nuestro autor en el proemio general, y vuelve a recordar los elogios de Celso a Hipócrates ${ }^{11}$.

9. Citamos por Daza Chacón, Dionisio. Prática y Teórica de Cirugía en Romance y en Latín. Valencia: Francisco Cipres; 1673. La «prefación» se extiende entre las páginas 1 y 40 y está dividida en nueve capítulos. Sobre ella puede verse Conde Parrado, Pedro. Ciencia y cultura clásica en la Cirugía española renacentista: el vallisoletano Dionisio Daza Chacón. Argaya. Revista de la Diputación Provincial de Valladolid. 1998; 14: 13-20.

10. Daza Chacón, n. 9, cap. I, p. 2.

11. Daza Chacón, n. 9, cap. I, p. 4-5, 7, 10. 
Como señalábamos más arriba, esos pasajes de Daza, así como los numerosos que alega de otros autores, son aducidos para demostrar la mayor antigüedad de la cirugía frente a las otras dos partes de la medicina. En una época en la que la antiquitas era sinónimo de verdad casi irrefutable y de preeminencia intelectual, es muy razonable que el tópico sobre la superior «solera» de esta disciplina no falte en prácticamente ningún proemio a obra quirúrgica del XVI; así mismo, resulta lógico que se aprovechasen las posibilidades de autorizar tal afirmación que brindaban los textos celsianos. Por ejemplo, la prefación de Peter Offenbach a su recopilación de importantes obras quirúrgicas del XVI ${ }^{12}$ fundamenta la superior vetustas de la cirugía reproduciendo sin mención de su origen el cuarto parágrafo del proemio al De med. (desde Nam Podalirius hasta proposuit). El mismo comportamiento se observa en el comienzo de la Chirurgia magna atribuida a Andrés Vesalio ${ }^{13}$.

Señalemos, en fin, cómo en todos los testimonios aducidos se observa un silencio absoluto sobre el hecho de que en ese mismo pasaje Celso también asignaba la categoría de antiquísima a la farmacia.

Después de su vetustas, el enciclopedista romano menciona en el proemio al libro séptimo el carácter «evidentísimo»de los resultados obtenidos por intervención quirúrgica, frente a los derivados de la acción de la dietética y de los medicamentos. Tampoco esto podía pasárseles por alto a los cirujanos, puesto que se trataba de una afirmación razonada de la preeminencia de su parcela profesional legada por una gran auctoritas antigua. Volviendo a la prefación de Daza y concretamente a su cuarto capítulo («En que se muestra la cirugía ser muy cierta y muy segura»), vemos cómo son de nuevo Hipócrates y Celso las dos primeras autoridades que se aducen para demostrarlo:

«En los males internos facilísimamente se puede engañar el físico (este es el propio nombre de los que ejercitan las dos primeras partes de la medicina), y así, por uno que se le muere al buen cirujano, se le mueren veinte al buen físico, porque más fácilmente puede errar. Esta es una cosa tan clara, que probarla sería gastar tiempo, y basta, para confirmación de todo, lo que dice Hipócrates: «Pocas veces acaece haber certidumbre precisa en la medicina».

12. Praefatio ad lectorem. In: Offenbach, Peter, ed. Thesaurus Chirurgiae, continens praestantissimorum autorum [...] opera chirurgica [...]. Frankfurt: N. Hoffmann-J. Fischer; 1610, p. 2-3.

13. La hemos consultado en Boerhaave, Herman, ed. Andreae Vesalii Opera Omnia Anatomica et Chirurgica [...] Tomus Secundus. Leiden: J. du Vivie et J. de H. Verbeek Bibliop.; 1725, p. 892. 
Y Cornelio Celso dijo: «La cirugía, entre todas las partes de la medicina, es la más evidente y más cierta», y allí lo prueba con razones bien bastantes» ${ }^{14}$.

Entre los cirujanos españoles de renombre que redactaron su obra en lengua latina podemos destacar el ejemplo de Andrés Alcázar (c.1490c.1585), quien abre sus Chirurgiae libri sex (1575) con un proemio «para encomio de la cirugía»; en él menciona la autoridad de Hipócrates, Galeno, Avicena, Vesalio y, por supuesto, Celso, de quien recoge los tópicos que venimos estudiando y los concentra en una única frase:

«A este propósito, alegaré aquella ilustrísima sentencia en la que Cornelio Celso, al comienzo del séptimo libro de su tratado médico, tanto encomia este oficio y lo pone por encima del resto: afirma que es el más antiguo y más eficaz, además de haber sido cultivado por el mismo padre Hipócrates; dice también que sus efectos son los más evidentes entre los de todas las partes de la Medicina» ${ }^{15}$.

\subsection{El cirujano, médico completo}

El precioso apoyo brindado por la obra celsiana en este proceso dignificador del quehacer de los chirurgi se completa con una de las frases del proemio al libro séptimo, que venía a mostrar cómo un cirujano completo posee una formación que engloba y supera a la del «físico»; en el primer parágrafo asegura Celso que la cirugía «tampoco deja de lado ni los medicamentos ni el régimen de vida», de donde era lícito colegir que el experto en esa disciplina debía serlo también en las otras dos. En el parágrafo quinto afirma su preferencia por el médico que, pese a las divisiones establecidas dentro de la profesión, no se limita a ejercerla en su parcela y trata de lograr dominio en las más de ellas.

Para Mariano Santo de Barletta (nacido en 1488), «el médico cirujano debe manejarse en todas las parcelas de la Medicina, como escribe Celso al principio de su libro séptimo» ${ }^{16}$. Gabriele Falloppio (1523-1562), en el Tractatus de ulceribus que se le atribuye, muestra su acuerdo con Celso

\footnotetext{
14. Daza Chacón, n. 9, cap. IV, p. 23.

15. La traducción es nuestra. Por razones de espacio, no se ofrecen los textos originales en latín, salvo cuando la argumentación requiera reproducirlos.

16. Compendium Chirurgicum, trat. II: De vulneribus. In: Offenbach, n. 12, p. 872.
} 
al responder a la cuestión sobre los límites de los conocimientos en los cirujanos:

«Así pues, el cirujano - en tanto que tal cirujano y porque no son obra de manos- no tendría por qué dominar la ciencia de los medicamentos ni saber sanar las enfermedades de las partes similares, que obedecen a un desequilibrio humoral. Pero alguno podría preguntar: ¿debe o no debe tener tales conocimientos? Yo respondo lo mismo que dice Celso: «siendo así que se han establecido especialidades médicas, mi alabanza va para aquel que abarca el mayor número de ellas». Yo aconsejo que el cirujano no desee ser sólo cirujano, sino médico completísimo. Yo, de hecho, no voy a enseñar aquí sólo el tratamiento quirúrgico de las úlceras, sino su curación integral: no como cirujano, sino como un médico tal, que abraza todas las facetas de su oficio» ${ }^{17}$.

Estos dos autores se limitan a ver el asunto desde la perspectiva de la formación completa e ideal del cirujano. Daza, dándola por supuesta, se muestra más estricto al introducir una triple división entre médico ideal, cirujano y «físico», en la que este último resulta ser el menos dotado en cuanto a extensión de conocimientos y en la que los dos primeros se identifican; las palabras de Daza van más allá de la simple reivindicación de la cirugía para convertirse en alegato contra una inmerecida superior reputación de los llamados «físicos»:

«Diréis ahora: "todo lo que habéis dicho y traído en alabar este arte se entiende de la medicina y no de la cirugía”; y es muy al contrario, porque los que curan con sola dieta y sangrar y purgar, su propio nombre es físicos, como arriba hemos dicho, y aún así los llaman hoy en muchas partes de nuestra España. Y los que propiamente son médicos y merecen este nombre son los que saben las primeras dos partes de la medicina dichas y la tercera, que es la cirugía: que tan bien y tan perfectamente está obligado un buen cirujano a saber las primeras dos partes de este arte, como está obligado a saber la tercera; y por esto dijo Cornelio: "No penséis que porque uno sea cirujano no esté obligado a saber dietar, sangrar y purgar al enfermo"» ${ }^{18}$.

17. Falloppio, Gabriele. Opera Omnia. Frankfurt: apud haer. A. Wecheli; 1600, p. 591.

18. Daza Chacón, n. 9, p. 23. A todo ello cabría añadir la gran influencia lograda por el «retrato del cirujano ideal» que Celso ofrece en De med. VII, proemio, 4. Véase Martín Ferreira, Ana I. El ideal de Celso en la cirugía española del siglo XVI. Medizinhistorisches Journal. 1995; 30 (2): 145-165. 


\section{Las doctrinas de Celso en la cirugía del Renacimiento}

Muy probablemente sea en el dominio de la Cirugía donde más se dejó sentir la influencia médica de Celso en la época renacentista. Sus doctrinas quirúrgicas, próximas muchas veces a las hipocráticas, y siempre expuestas con claridad y precisión, le aseguraron una presencia destacada en los más importantes textos dedicados a esa disciplina.

Johan Rodhe (1587-1659), autor ya en el siglo XVII de una biografía de Celso, al afrontar la cuestión del origen profesional de sus saberes médicos ${ }^{19}$, afirma que es precisamente el conjunto de los que demuestra en cirugía la mayor prueba de que fue un verdadero médico ${ }^{20}$.

A comienzos del siglo XVI, Giovanni da Vigo (c.1450-1525) proclamaba que el creador del De med. es un vir elegantissimus, et in arte Chirurga utilissimus $^{21}$, facundissimus en sus enseñanzas ya celebérrimas ${ }^{22}$ y de una insuperable auctoritas ${ }^{23}$. Elogios que tienen su reflejo en una obra quirúrgica como la de Vigo, en la que es Celso la principal autoridad tanto antigua como moderna, teniendo en cuenta que su nombre se menciona explícitamente en más de una treintena de ocasiones. Es este un dato de suma importancia, así como que Vigo subraye la «celebridad» de algunas propuestas quirúrgicas celsianas, si se tiene en cuenta que compuso su obra no mucho después de la editio princeps del De med. (1478). La gran influencia de la Practica de Vigo en la cirugía del siglo XVI era así garantía de difusión de la letra y la doctrina quirúrgicas de Celso.

En la obra del cirujano italiano, además, apenas se observa la presencia - explícita, al menos - de los «dioses de la medicina» Hipócrates y Galeno, lo que invita a pensar que ya desde este tratado se apunta una predilección hacia Celso de la «nueva» cirugía, por encima de esos autores griegos ${ }^{24}$.

19. Es decir, la debatida cuestión (ya lo era en el Renacimiento) de si Celso fue médico profesional; véase Conde Parrado, Pedro; Martín Ferreira, Ana I. Estudios sobre Celso. Problemas metodológicos y estado de la cuestión. Tempus. 1998; 20: 5-80 (29-31).

20. Citado en la Vita Celsi de Johan Rodhe, reproducida en A. Corneli Celsi. De medicina libri octo ad optimas editiones collati. Praemittitur notitia literaria [...]. Biponti (Zweibrücken): Ex Typographia Societatis; 1786, p. VIII-IX.

21. Vigo, Giovanni da. Practica. Lyon: Carolum Pesnot; 1582, p. 493.

22. Vigo, n. 21, p. 772.

23. Vigo, n. 21, p. 807.

24. No obstante, debemos tener en cuenta que en el caso de Hipócrates y, sobre todo, de Galeno la cirugía es la parte de la medicina menos y peor atendida. En el mundo medieval, la gran autoridad quirúrgica fue realmente Pablo de Egina con su compendio de textos médicos 
Así, conviene saber que no fue la de Vigo la única manifestación en tal sentido: otro de los grandes expertos en la materia, Jean Tagault (fallecido en 1545), en las Institutiones Chirurgicae en las que revisó y actualizó la obra sobre cirugía más importante del Bajo Medievo, la Chirurgia magna de Guy de Chauliac, expuso las líneas maestras de tal tarea, señalando que una de sus principales facetas - típicamente humanista-consistía en pasar la obra de Cauliacus por la «criba» de las obras antiguas, especialmente de una de ellas:

«A partir de las purísimas fuentes de los griegos Hipócrates, Galeno, Pablo de Egina y Ecio de Amida, y de los muchísimo más eruditos y elegantes libros de Cornelio Celso sobre la Medicina, hemos enriquecido, ilustrado y despojado de sus torpes falsedades e increíbles errores, que lo afeaban por doquier, el tratado sobre cirugía de Guy» ${ }^{25}$.

Así pues, Tagault se habría servido de los autores griegos como garantes de la pureza doctrinal de cuanto recoge en su obra y de Celso como del gran expositor que, a mucha distancia del resto (longe), supo reunir la erudición con la elegancia. De Tagault podemos señalar, pues, la misma actitud «celsista» que observábamos en Vigo: sus alusiones a Celso y su doctrina quirúrgica son casi innumerables, y ello sin tener en cuenta los muchos pasajes que revelan un aprovechamiento no declarado. Esto supone que su influjo sobre esta obra iguala y en muchas partes supera al del mismo Galeno.

Y si impagables resultan los testimonios de Vigo y Tagault para percibir esa veneración, no menos importante es el modo como otro de los grandes, Guido Guidi (o Vidus Vidius) (c.1500-1569), concluye su traducción y comentario al escrito hipocrático De vulneribus capitis; después de haber mencionado a Celso en varias de sus anotaciones al texto, de haberse inspirado en su estilo y de haber recurrido al léxico por él empleado, se adelanta a quien pudiera reprocharle «tanto Celso», justificando haber

redactado en el siglo VII. Ello ayuda a explicar que fueran Celso y el Egineta las dos principales auctoritates hacia las que volvió su mirada la cirugía renacentista para recabar doctrinas quirúrgicas (las citas de Galeno son muy abundantes en cualquier tratado sobre cirugía en la centuria, pero cabe preguntarse cuántas de esas menciones hacen referencia a asuntos relacionados estrictamente con esa disciplina).

25. Tagault, Jean. Institutionum Chirurgicarum libri quinque quibus totum Guidonis Cauliaci volumen chirurgicum continetur [...]. In: Offenbach, n. 12, p. 665. Nuestra traducción. 
acudido a él porque «muchas operaciones apenas podrían llevarse a cabo si no se lo consultara» ${ }^{26}$.

Así pues, también Guidi parece conceder a Celso una primacía intelectual entre las autoridades antiguas que han legado conocimientos en materia quirúrgica; ello equivale, en esos momentos de casi «idolatría» y «sometimiento» al saber greco-latino, a otorgárselo igualmente de manera absoluta para todas las épocas. No es escaso mérito para un verdadero «recién llegado»a la escena científico-literaria del Renacimiento, cuya obra había permanecido oculta, sin poder crear tradición, desde la tardía Antigüedad hasta comienzos del siglo XV. Y todo lo debe, sin duda, a las enormes calidades de la parte de su enciclopédica obra que venció a la «injusticia» del tiempo, el De medicina.

\subsection{Celso y la osteopatología: las lesiones craneales y la fractura apéchema}

A tenor de lo expuesto hasta aquí, se comprenderá fácilmente que pretender dar cuenta exhaustiva de la influencia celsiana en las obras de asunto quirúrgico del siglo XVI excedería con mucho los límites de este trabajo. Por ello, hemos efectuado una selección de cuestiones habitualmente tratadas en dichas obras y en las que la mención de las doctrinas de Celso, para aceptarlas o para refutarlas, es una constante.

En primer lugar, hemos analizado la influencia ejercida por ciertos lugares del último libro del De med. en los pasajes sobre patología ósea. Estudiaremos, en especial, las lesiones craneales, a las que, por su importancia sobre el resto de las osteopatías, se prestó singular atención en la cirugía renacentista.

El libro octavo del De med. se abre con un breve y preciso estudio del esqueleto humano (cap. I): estudio concebido como mínimo soporte de conocimientos anatómicos para la exposición patológica que ocupa el resto del libro 27 .

26. Guidi, Guido. Chirurgia e Graeco in Latinum conversa [...] cum nonnullis eiusdem Vidii commentariis. París: Petrus Galterius; 1544, p. 130.

27. La influencia de esta «anatomía» de Celso en la Anatomía renacentista puede verse en Conde Parrado, n. 3, p. 219-305. 
El capítulo cuarto, que es, junto con el décimo, el más extenso del libro, se centra en las lesiones generales que pueden acaecer en el cráneo, la región más delicada por el órgano que protege. Este fue, sin duda, el capítulo del libro octavo que mayor influencia ejerció en la Cirugía renacentista.

Aconseja Celso, ante todo, atender a los síntomas tanto externos como internos del herido para detectar si ha habido rotura de algún hueso del cráneo, y, seguidamente, indagar las características del objeto que la haya producido $(\$ 2)$; esto es, como bien señala Andrés Alcázar, buscar la tradicional causa eficiente del aristotelismo escolástico:

«Así pues, el primer indicio se obtiene de la causa eficiente, es decir, si ha sido por un arma arrojadiza o por algún otro objeto causante de la herida [...] o por una caída, tal como enseña Cornelio Celso en el libro 8, capítulo 4. [...] Y el mismo Cornelio, en el pasaje citado, dice: "ante todo, se ha de considerar si ha sido golpeado por piedra, madera, hierro o cualquier otro objeto arrojadizo y, además, si era el objeto liso o rugoso, si de tamaño pequeño o grande, si se golpeó con fuerza o levemente" ${ }^{28}$.

En el tratado de cirugía atribuido a Andrés Vesalio ${ }^{29}$, se expone un asunto bastante discutido en la época y en el que la auctoritas celsiana tuvo también gran peso: la posibilidad de que el cráneo reciba un golpe en un lado y aparezca después herido e incluso quebrado en una parte diferente. Celso, en efecto, declara en el sexto parágrafo del mismo capítulo: «Suele suceder también que el golpe se produzca en una parte y el hueso se hienda por otra» ${ }^{30}$.

La existencia real de ese tipo de fractura, conocida en griego como apéchema, constituyó un dubium al que se dedicó no poco espacio en casi todos los tratados de cirugía importantes en la época; en la gran mayoría se alegan las teorías al respecto de Hipócrates, Sorano de Éfeso, Galeno, Pablo de Egina, el medieval Nicolaus Florentinus (Nicolò Falcucci) y Celso, cuya presencia es verdaderamente indefectible.

Lo que hace de esta clase de fractura un accidente de naturaleza tan debatida es, sin duda, la ambigüedad con que fue formulada por Hipócra-

28. Alcázar, Andrés. Chirurgiae libri sex. Salamanca: Dominici a Portonariis; 1575, p. 21. Nuestra traducción.

29. En Offenbach, n. 12, p. 941.

30. Solet etiam evenire, ut altera parte fuerit ictus, et os altera fiderit (Celso, De med., lib. VIII, cap. IV). Como veremos, la clave del pasaje reside en el empleo del adjetivo altera («una de las dos partes de algo»), que no es lo mismo que alia («otra parte», sin más). 
tes ${ }^{31}$ y recogida por Celso; fijándonos en las palabras arriba consignadas de este último, observamos que no puede saberse si se habla de un golpe en un hueso del cráneo con fractura en otro hueso de este o si la fractura se verifica en otra parte del mismo hueso; es evidente que el empleo de altera remite a las dos partes de una única realidad, pero ¿es esta todo el cráneo o solo uno de sus huesos?

En la medicina posterior a Hipócrates y Celso, Sorano de Éfeso defenderá la posibilidad de que el cráneo se fracture en la parte opuesta, al modo de los recipientes de vidrio, lo que negará Pablo de Egina apelando a la constitución ósea del cráneo transmitida por Galeno ${ }^{32}$. De entre los varios tratados renacentistas de cirugía que contemplan este asunto hemos escogido como muestra la Cirugia Universal de Juan Fragoso (fallecido en 1597), dada la sucinta y, a la vez, completa exposición del problema que brinda al lector moderno:

«Questión es si este genero de fractura de Hipócrates (llamada contrafisura o fractura de oposición o respuesta de eco) acontece algunas veces, visto que Paulo la reprueva como imposible, porque, aunque dixo Sorano que, hiriendo en una parte la cabeça, se puede quebrar la contraria como en el vidrio, responde a esto que la fractura llamada apechema [...] ni la ay, ni es buena la comparación del vidrio, porque es vazío, y el casco [el cráneo] lleno de todas partes [...] Y esta doctrina es más segura y llegada a razón, pues dize Galeno ${ }^{33}$ que el casco no fue cerrado y sus comisuras porque, tocando en una parte, no se ofendiese mucho del hueso, lo qual aconteciera, si fuera todo firme. Y así, entre los otros provechos de las comisuras, es este muy

31. En De vulneribus capitis, cap. VIII (III 210 L.): «El hueso se hiende en una parte de la cabeza distinta a aquella donde el paciente tiene la herida». Según indica Falloppio en su Expositio in Galeni de ossibus, n. 17, p. 488, la importancia de solucionar ese dubium reside en que, si no es así, el médico no sabe en qué parte del hueso debe aplicar los medicamentos.

32. En realidad, que Pablo de Egina se apoyara en la doctrina anatómica de Galeno, si bien es verosímil, no pasa de ser una suposición de algunos autores renacentistas, pues en ningún lugar del capítulo 90 de su sexto libro (que es lo que parafrasea Fragoso en el texto que luego citamos) menciona Pablo al de Pérgamo: «Algunos añaden a estos tipos de fracturas craneales el apechema. [...] Pero se engañan, porque no sucede en el cráneo humano lo mismo que ellos afirman que se produce en algunos recipientes de vidrio, puesto que estos son vacíos y por ello se ven expuestos a ello, pero el cráneo humano está relleno y, además, es bien sólido» (traducimos a partir de la versión latina de Johan Guenther von Andernach. Pauli Aeginetae Medici Opera. Estrasburgo: Vuendelinum Rihelium; 1542, p. 317). La opinión de Sorano se encuentra en Fract. 8, según el diccionario griego-inglés de Liddell y Scott, s.V. apécheia (p. 189).

33. Al margen anota: «Lib. 9 de usu partium c. 7». 
principal: que quando el golpe descarga en una parte, no pase a otra, sino que se acabe en la misma comisura» ${ }^{34}$.

Después Fragoso propone una aclaración de la ambigüedad patente en Hipócrates y en el pasaje celsiano, que fue la que, en general, se aceptó por quienes trataron el problema con una cierta detención y profundidad:

«Conforme a lo qual podremos dezir que Hipócrates no entendía de parte contraria, pasada la comisura (como, si el hueso coronal esta herido, que se quiebre el occipital, o al contrario), sino de otra que esté dentro del término della, en el mismo hueso a donde alcança la herida: y desta manera entendió tambien Celso, quando dixo ser posible darse a una parte la herida, y a otra henderse el hueso» ${ }^{35}$.

Sin embargo, no podía pasarse por alto que un importante autor tardomedieval como Niccolò Falcucci (Nicolaus Florentinus) hubiera defendido, alegando su propia experiencia, la verdad de esas fracturas craneales in parte opposita ${ }^{36}$. Fragoso, aunque no niega que Falcucci atendiera un caso de ese tipo, lo achaca, bien a que existieran en realidad dos golpes en partes opuestas, de los que uno quedó oculto, bien a que el golpe fuera tan grande que se abrieran las suturas sin herida aparente, pero provocando una inflamación letal, lo que habría inducido a pensar en una herida en otra parte que en realidad no existió; reconoce Fragoso que esa segunda explicación es la que ya había apuntado Luis Mercado (1525-1611) en su libro de cirugía ${ }^{37}$.

Así pues, a Celso puede atribuírsele una innegable ambigüedad, pero no se puede afirmar que de su doctrina se dedujera claramente la posibilidad de una fractura en la parte de la cabeza opuesta a la golpeada; es claro que

34. Fragoso, Juan. Cirugía universal, ahora nuevamente enmendada y añadida en esta sexta impressión [...] más otros cuatros tratados. Alcalá de Henares: en casa de Juan de Gracián; 1608, p. 314-315.

35. Otros autores que ofrecen esa interpretación son Díaz, Francisco. Compendio de Chirurgía. Madrid: en casa de Pedro Cosin; 1575, p. 229; Alcázar, n. 28, p. 19; y, antes de ellos, Guidi, n. 26, p. 72. De hecho, la exposición de Guidi es muy similar a la de Fragoso, quien bien pudo tenerlo como fuente; no en vano fue Guidi el primero y uno de los principales divulgadores en el siglo XVI del tratado hipocrático sobre las heridas craneales.

36. El testimonio de Falcucci se halla en el séptimo de su De medica materia septem sermonum liber. Venecia: Luceantonii Junte; 1533, p. 131-132.

37. Mercado, Luis. Institutiones Chirurgicae iussu regio factae pro chirurgis in praxi examinandis. Madrid: Ludovicus Sanchez; 1594, p. 69. 
todo dependía del alcance que se diera en ese pasaje celsiano al adjetivo altera; esto es, si se equiparaba a un también ambiguo alia o se entendía más bien como opposita. A nuestro criterio, tiene razón Falloppio cuando señala, como después hará Fragoso, que Hipócrates (y, por tanto, también Celso) «no dice que el hueso se quiebre en la parte opuesta, sino que dice "en otra parte", y no es lo mismo "en otra parte" que "en la parte opuesta"; pues si la frente se rompiera por la mitad, se romperían también las zonas próximas, pero no la parte opuesta [a la frente, es decir el occipucio, por ejemplo]».

Sin embargo, no faltaron testimonios que defendieran la realidad de esa «contra-fractura» en un hueso craneal diferente, apoyándose asimismo en el testimonio de Celso, entre otros, y en la experiencia propia. Así, Luis de Lemos (c.1530-post 1585) afirma haber asistido en persona a la observación de un caso de ese tipo en Granada. Su testimonio es importante, puesto que en la experiencia que relata se muestra como observador de una práctica quirúrgica de la que extrae conclusiones teóricas:

«En Granada, hace unos años, vimos a un joven que había sido herido en la parte izquierda de la cabeza, la cual le fue explorada hasta descubrir el cráneo, pero no apareció fractura alguna. Como su padecimiento no cesaba, sino que aumentaba de día en día, pensamos que tenía fracturado el cráneo en la parte derecha de la cabeza. Los cirujanos, que eran también de esa opinión, se la abrieron por esa zona y allí se halló una fisura bastante visible: de ello deduje que era cierta la opinión de Celso y otros en el sentido de que, en la cabeza, puede haber golpe en una parte y fractura en otra» ${ }^{38}$.

\subsection{Celso y la cirugía "vulneraria»: las heridas mortales}

En el primer párrafo de este estudio señalábamos que Celso había excluido de sus libros «quirúrgicos» (VII y VIII) el tratamiento de las heridas (al que dedica pasajes en el libro V, caps. 26 y 27), aun siendo un quehacer reclamado por los cirujanos. El lugar en que lo afirma (De med. VII, proemio, 5) se complementa con uno anterior en que lo anuncia: en V 26,1B, después de exponer los cinco géneros en los que, según él, se reparten las

38. Luis de Lemos. In libros Galeni de morbis medendis commentarii. Salamanca: Mathiae Gastii; 1581, p. 217. Nuestra traducción. 
lesiones corporales, afirma que va a tratar de aquellas que necesitan más del medicamento que de la operación manual, dejando lo que, según él, es específicamente quirúrgico para los libros séptimo y octavo, y comenzando por el estudio de las heridas.

Los cirujanos escritores del siglo XVI continuaban incluyendo en sus obras el tratamiento tanto farmacológico como quirúrgico de las heridas y, por tanto, reivindicándolas, como sucedía en época de Celso.

Por otra parte, la recomendación de inhibirse en los casos desesperados (De med. V 26,1C), que logró mucha resonancia en la literatura médica del Renacimiento y, sobre todo, entre los cirujanos ${ }^{39}$, sirve a Celso para introducir una exposición sobre las heridas en función de su gravedad, según el órgano afecto, que ocupa los primeros diecinueve parágrafos de ese vigésimo sexto capítulo del libro quinto.

La cirugía del siglo XVI mostró una rendida admiración por ese conjunto de datos sobre los vulnera, muchos de ellos basados en textos hipocráticos ${ }^{40}$. Es perfectamente explicable que en una época de gran agitación bélica, en la que los mejores autores de tratados quirúrgicos se distinguieron como eminentes cirujanos de campaña, se observen actitudes muy «agradecidas» hacia una exposición tan antigua, elegante y precisa como la de Celso. Son frecuentes afirmaciones rotundas y elocuentes en ese sentido, y no precisamente en autores de segunda fila.

Así, Daza Chacón brinda un testimonio de la alta estima y aprovechamiento de esos pasajes celsianos por parte de él mismo y de sus colegas:

«También puso [Pablo de Egina] estas señales [de los tipos de herida], pero el que mejor las puso, y de donde todos las tomamos, fue Cornelio Celso» ${ }^{41}$.

El segundo libro de las Institutiones Chirurgicae de Tagault porta el título De vulneribus, y el tercero de los capítulos de este, el de De signis et iudiciis vulnerum. Después de tratar ese asunto con varias referencias a Celso, cierra el capítulo reconociendo las excelencias de su exposición sobre los vulnera y, lo que es más importante, cediéndole la palabra:

39. Véase Conde Parrado, n. 3, p. 111-116.

40. Así, el aforismo VI 18 [IV 566-568 L.] o las Predicciones de Cos IV 19 [V 699 L.].

41. Daza Chacón, n. 9, 1673, parte II, p. 15-16. Véase también p. 18. 
«Así pues, daremos buen fin a estos pronósticos sobre las heridas, si rematamos con lo que de manera sabia, precisa y bien adornada escribió Celso al respecto. Ello servirá como una especie de resumen y compendio de cuanto hasta aquí hemos expuesto sobre los pronósticos en heridas. Estas son sus palabras» ${ }^{42}$.

$\mathrm{Y}$ a renglón seguido reproduce un extenso pasaje que comprende los parágrafos dos a cuatro de De med. V 26 (desde Servari non potest hasta magnum est).

Estos dos autores, como era habitual en toda exposición sobre las heridas, recuerdan también el texto previo de carácter deontológico sobre los casos incurables. Era evidente que el cirujano debía por fuerza conocer la gravedad que podía alcanzar cualquier herida, junto con sus efectos, tanto para curarla, como para «curarse en salud» no intentando una intervención que pusiera en peligro su reputación e, incluso, su inocencia ante la muerte del herido. A este respecto, el cirujano que suscita mayor interés es Juan Fragoso, por haber asentado las bases de la cirugía legal en uno de sus Tratados ${ }^{43}$ añadidos a su Cirugia Universal. Además de ser Celso la primera autoridad antigua que cita («Por lo qual avisa Cornelio Celso [V $26,1 \mathrm{C}]$, que primero averigüemos si la enfermedad tiene cura dificultosa, porque es de cirujano prudente...»), recuerda algunos de los pasajes del $D e$ med. que pueden ilustrar y guiar al cirujano en ese ineludible y trascendental menester ${ }^{44}$.

\subsection{Influencia de Celso en dos tipos de intervenciones quirúrgicas}

En este apartado queremos dar cuenta de la influencia del De med. en dos de las más habituales operaciones a las que debía - y aún debe hoy- enfrentarse cualquier cirujano. En ellas, el método propuesto por Celso fue no solo tenido en cuenta, sino también practicado con asiduidad; en no pocas ocasiones, además, fue preferido al que se lee en otras importantes obras quirúrgicas antiguas, como la de Pablo de Egina.

\footnotetext{
42. En Offenbach, n. 12, p. 739. Nuestra traducción.

43. Concretamente, en el segundo: Summa de las proposiciones que han de hazer los cirujanos, acerca de muchas maneras de muertes que suceden (hay edición moderna a cargo de J. Corbella [Barcelona: PPU; 1988]).

44. Fragoso, n. 34, p. 539-576. Véase Mercado, n. 37, p. 69.
} 
Algunas de esas intervenciones se habían dejado hacía tiempo en manos de sanadores especializados, con una actividad más o menos ambulante; los cirujanos renacentistas vuelven a dotarles de su condición de nobles operaciones quirúrgicas y lo hacen, en buena medida, apoyándose en su importante presencia y su completa descripción en el De medicina.

\subsubsection{La gangrena}

Son dos los lugares del De med. en los que Celso se ocupa de la gangrena. El motivo es, de nuevo, que la considera un mal susceptible de ser sanado por medio tanto del medicamento como de la cirugía, siempre sucesivamente y una vez que el primero haya demostrado su ineficacia. Y de nuevo es en el importante capítulo vigésimosexto del libro quinto (parágrafo 34) donde encontramos la exposición sobre el método farmacológico para sanar este mal. Resulta curioso y trágico, a la vez, que una afección que es de fácil cura en sus comienzos, según Celso, tenga en ocasiones un final tan terrible como la necesidad de amputar el miembro dañado. Al comienzo de ese pasaje se consignan las condiciones que influyen en la pronta solución de tal morbus, como la edad del paciente o la parte del cuerpo afectada.

En el último capítulo del libro séptimo, después de consignar los indudables y graves peligros que conlleva la amputación (hemorragia y pérdida del conocimiento), asegura Celso que no hay más posibilidad que arriesgarse: «Pero, llegados a ese punto, nada importa si [amputar] es o no un buen remedio, porque no hay otro» ${ }^{45}$.

En la literatura quirúrgica del período renacentista es muy habitual el recuerdo de estas palabras al tratar sobre la gangrena, un mal para el que nadie, que sepamos, propuso otra solución que cortar el miembro afectado cuando no quedaba más remedio. Aunque no se puede en absoluto adscribir

a Celso una idea perteneciente al acervo común de la Medicina, lo cierto es que de nuevo su precisión «aforística» y la forma en que se expresa, bella y contundente a la vez, fueron lo que dotó a la formulación celsiana de tan gran predicamento en los textos médicos. Así, en Daza:

45. De med., VII 33,1. Este pasaje forma parte, junto a varios otros, del conjunto de importantes cuestiones deontológicas que Celso plantea y que tuvieron muy amplio eco en la literatura médica renacentista. Véase Conde Parrado, n. 3, p. 111-118. 
«Pero ciertamente cosa miserable es haber de cortar todo el miembro que poco a poco se va muriendo (que no hay otro remedio) para salvar y guardar la vida de los otros, como dice Cornelio; lo qual también dixo Albucasis, aunque no por tan elegantes palabras; de manera que, como dice Cornelio, esta es cura de gravísimos casos, y áspera, pero no hay otra: hase de hacer, pues no tenemos otro camino para escapar la vida al enfermo; y por esto dixo muy bien Cornelio en el lugar alegado: quando no hay más de un remedio para una enfermedad, no habéis de inquirir si es peligroso o seguro, ni si es áspero o liviano, sino andar adelante y efectuar» ${ }^{46}$.

Jean Tagault en sus Institutiones Chirurgicae ${ }^{47}$ y Francisco Díaz (c.1510c.1588) en su Compendio de Chirurgia ${ }^{48}$ remiten, así mismo, a Celso al afirmar que la amputación es el único remedio posible en muchos casos de gangrena. La Practica de Giovanni da Vigo lo menciona nada menos que en tres ocasiones distintas, afirmando en la segunda que Celso es el autor «más elegante y útil en el arte de la Cirugía» ${ }^{49}$.

Volviendo a Celso, hay que decir que, frente a lo que sucede con la doctrina anterior, el acuerdo con él fue mucho menos generalizado en el caso de otra afirmación suya a propósito del método de amputación; en VII 33,1 inicia la exposición de dicho método con el que será un polémico consejo en el Renacimiento:

«Así pues, con el escalpelo se ha de cortar hasta el hueso la carne que hay entre la parte sana y la parte afecta; [... y es mejor llevarse algo de la parte sana que dejar sin cortar algo de la dañada».

En los textos médicos del Renacimiento tenemos, por ejemplo, a Fragoso, quien, en la parte de su Cirugia Universal en que trata en general sobre la gangrena, menciona solamente a Celso como autoridad, recordando su consejo («solo un remedio, aunque miserable, como dice Celso: que es cortarle por salvar todo el cuerpo») ${ }^{50}$. Pero más adelante, al plantear la cuestión «Si el miembro corrompido se ha de cortar por lo sano o ha de quedar algo de lo dañado» ${ }^{51}$, expone las razones que se pueden aducir a favor de lo uno $y$

\footnotetext{
46. Daza Chacón, n. 9, p. 179.

47. En Offenbach, n. 12, p. 699. Tagault reproduce completo todo el pasaje De med. V 26,34.

48. Díaz, n. 35, p. 118.

49. Vigo, n. 21, p. 80, 493, 851.

50. Fragoso, n. 34, parte I, p. 75.

51. Fragoso, n. 34, parte II, p. 225-226.
} 
de lo otro, alegando a Celso como única autoridad que defiende la primera parte de la cuestión citada (cortar «por lo sano») y a Giovanni da Vigo y Gabriele Falloppio como partidarios de la tesis contraria.

Tal dato es cierto: lo de Vigo puede leerse en el segundo de los pasajes a los que aludíamos más arriba. Falloppio lo expone en el capítulo 26 del Tractatus de tumoribus praeter naturam ${ }^{52}$. Su rechazo a la opinión de Celso es, nunca mejor dicho, tajante, pues afirma que «no es aceptable»y que es, incluso, «condenable». Como contamos con la versión del pasaje falopiano en el siempre excelente castellano de Fragoso lo ofreceremos con las palabras de éste:

"Cornelio Celso dice que entre la parte sana y entre la dañada se ha de cortar con navaja hasta el hueso, y que antes se ha de cortar por lo sano que dejar de lo dañado. Falopio reprehende a Celso, diciendo que de cortar por lo sano se sigue pasmo, fluxo de sangre, desmayos y dolor intensísimo».

Señala después Fragoso (pero siempre tomándolo de Falloppio, en realidad) que el problema que se plantea es que la separación entre parte sana y parte afecta no es casi nunca nítida, por lo que, como dice Galeno, «no se hace [el corte] tan exquisítamente, que se llegue a lo bueno sin daño dello» ${ }^{53}$; por eso habría que cortar siempre tendiendo a no tocar lo sano, por lo que siempre es posible que quede parte de lo dañado sin extirpar. Y es que la disensión «milimétrica» se plantea entre quienes, como Pablo de Egina y Ecio de Amida, postulaban cortar «lo más cerca de lo sano», pero sin tocarlo, y entre quienes preferían sacrificar parte de lo sano con tal de no dejar rastro de lo enfermo, como Celso.

La doctrina del enciclopedista romano halló también decididos partidarios entre los cirujanos del Renacimiento. Un claro ejemplo es el de Ambroise Paré (c.1510-1590), quien apoya el orden de Celso, planteando, además, el dilema deontológico al que se enfrenta el cirujano, así como un ejemplo de actuación en un caso concreto; la incisión en parte sana se da ya por supuesta desde el principio, dado que la cuestión que se debe dirimir versa acerca de la cantidad de esa carne sana que se ha de cortar:

\footnotetext{
52. Falloppio, n. 17, p. 664-665.

53. Fragoso señala al margen la fuente galénica: «Libr. 2 ad Glauconem cap. 10 [...] li. 3 de morbis popularibus, comment. 3 section 4» (véase XI 136 K.).
} 
«Nuestra arte ordena cortar el miembro por la parte sana de la carne; pero esa misma arte ordena también que conservemos íntegro, en la medida de lo posible, cuanto en el cuerpo hallemos sano. Cómo has de conducirte en estas dificultades te lo mostraré con un caso habitual: supongamos que una gangrena se apodera de un pie hasta el tobillo: tienes entonces que decidir con exactitud por dónde has de cortar. Pues bien, si no incluyes en la amputación carne viva y dejas el mínimo fragmento de carne putrefacta, nada habrás logrado amputando, puesto que aquella se extenderá sin tardanza al resto del cuerpo. Es cierto que en la medicina, nacida para preservar el cuerpo humano, conviene mantener el hierro y todo posible daño alejado al máximo de aquello que goza de vida y salud. Por tanto, amputarás lo menos posible de la parte que está sana: ahora bien, de manera que antes quites de la parte sana que dejes algo de la enferma, tal como nos aconseja Celso» ${ }^{54}$.

\subsubsection{El cálculo en la vejiga}

No podíamos dejar de lado en esta aproximación la influencia de Celso sobre los métodos de extirpación del calculus in vesica. Sobre todo, si se tiene en cuenta que la técnica que propone, similar a la que posteriormente expondría Pablo de Egina (lib. VI, cap. 60), mantuvo una vigencia milenaria, precisamente hasta los siglos XVI-XVII en que comienza a abandonarse o, más bien, a perfeccionarse precisamente a partir de las doctrinas casi recién halladas de Celso. Señalemos que la parte del De med. dedicada a la extracción del cálculo es todo el vigésimo sexto capítulo del libro séptimo, «uno de los más largos y complejos pasajes de sus libros de cirugía» 55 .

Entre los cirujanos renacentistas podemos destacar el caso del pionero de la cirugía plástica, Gaspare Tagliacozzi (1545-1599), quien, pese a considerar que el procedimiento de Celso es demasiado doloroso y arriesgado, reproduce, como único testimonio de métodos de extracción, nada menos que la segunda parte (parágrafos A-O) de De med. VII 26, reconociendo que esta litotomía es «culmen y suma de todas las operaciones quirúrgicas» ${ }^{56}$.

\footnotetext{
54. Offenbach, n. 12, p. 276. Nuestra traducción.

55. Jackson, Ralph. Doctors and diseases in the Roman Empire. Londres: British Museum Press; 1988, p. 125.

56. Manget, Jean Jacques. Bibliotheca Chirurgica. Ginebra: Perachon et Cramer filii; 1721, p. 422423.
} 
Pero en este caso, para comprobar la extensión, asimilación y consolidación de la técnica propuesta por Celso, vamos a exponer el modo como los cirujanos del siglo posterior presentan el panorama de los diferentes procedimientos de extracción que se fueron planteando por parte de sus antecesores del siglo XVI.

Para Charles Drelincourt (1633-1697), autor de una Disputatio Medica de Calculo Vesicae, la técnica celsiana continuaba situándose por encima de las que recientemente habían sugerido autores como Fabry von Hilden (1560-1634): «Que impere sólo, pues, ese método de extirpar el cálculo que agrada a tantos prácticos excelentes y, sobre todos ellos, a Celso» ${ }^{57}$. Thomas Feyens (1567-1631), por su parte, nos ilustra sobre los dos métodos más empleados en su tiempo:

«Dos son los principales métodos de esta operación: uno es el llamado Celsístico o Guidoniano, el cual transmitieron Celso y Guy [de Chauliac] ${ }^{58}$, y es el que los prácticos llaman operación de menor aparato, puesto que se efectúa de modo fácil y sin mucho instrumental: se introducen los dedos en el ano y se practica una simple incisión sobre el propio cálculo. [...] La otra se denomina operación Mariana, pues el primero que la enseñó fue Mariano Santo de Barletta, a quien se la había mostrado su maestro Giovanni, famoso cirujano, y es la que los prácticos llaman operación de mayor aparato, puesto que es muy trabajosa y requiere de un gran número de instrumentos» ${ }^{59}$.

Realmente prolijo y complejo es, en efecto, el método que propone Santo de Barletta en su Libellus aureus de lapide ex vesica per incisionem extrahendo ${ }^{60}$; en él presenta la descripción y el dibujo de una decena de instrumentos quirúrgicos (el apparatus maior) que deben emplearse en la técnica que recomienda, confirmando plenamente las palabras de Feyens. Señalemos que la única disensión con Celso que expresa Santo, quien demuestra con ello tenerlo bien presente, se refiere al modo como debe practicarse la incisión perineal: en opinión de Celso, debía efectuarse «en forma de media luna y a lo ancho» (De med. VII 26,2H); para Santo, que no especifica la forma que debe adoptar la incisión, es mucho más recomen-

\footnotetext{
57. Manget, n. 56, p. 226. Nuestra traducción.

58. La técnica propuesta por Guy de Chauliac se puede leer en su Chirurgia magna, tract. VI, doctr. II, cap. 2. In: McVaugh, Michael, ed. Inventarium sive Chirurgia magna. Leiden-Nueva YorkColonia: Brill; 1997, p. 343-344.

59. De praecipuis artis chirurgicae controversiis, Manget, n. 56, p. 247-248. Nuestra traducción.

60. Offenbach, n. 12, p. 909-942.
} 
dable el corte longitudinal, que hace mucho más fácil el cierre de la herida; la reprehensio de este cirujano hacia Celso es, con todo, muy «cariñosa»:

«Por lo cual, me extraña que otros autores $-\mathrm{y}$, sobre todos, tú, mi querido Cornelio Celso- ordenen hacer la incisión en sentido latitudinal a los pliegues; [...] cuando, si la hacemos en sentido longitudinal a dichos pliegues, resulta admirable la rapidez con que se unen y cierran los bordes de la herida» ${ }^{61}$.

\section{Conclusiones}

En las páginas precedentes hemos querido mostrar, siquiera parcialmente, cómo uno de los ámbitos del ejercicio médico renacentista que mayor utilidad teórica y práctica recibió entre las excelencias del De med. de Celso fue la actividad quirúrgica. Como señalábamos al comienzo, la índole de su quehacer sanador había relegado a los cirujanos a la condición de meros ejecutores de tareas mecánicas muy poco agradables. Mientras un físico podía limitarse a visitar enfermos, escrutar orinas, tomar pulsos y ordenar la confección de medicamentos, el cirujano debía actuar casi siempre tomando arriesgadas y mal recibidas decisiones sobre la marcha, en permanente contacto con la sangre y el dolor; un dolor que muchas veces se veía obligado a causar él mismo. Esta situación profesional los impelió a elevar la categoría de su oficio por encima del de simples sanadores: a aparecer, en definitiva, como médicos completos y rationales que, por methodus, sabían qué humores habían provocado un apostema, contra qué morbus valía cada simple o cuál era el mecanismo anatómico de una articulación luxada, y no como «empíricos» que fiaban todo a una experiencia que podía fallarles con resultado trágico. Su situación se tornaba aún más delicada si se tiene en cuenta que en un oficio esencialmente manual como el suyo esa experiencia resultaba imprescindible para que su saber no fuera solo libresco y, por tanto, estéril.

En ese contexto profesional descubrieron los cirujanos una obra como el De med., que atesoraba una serie de valores impagables para su quehacer médico: escrita en época clásica y en excelente latín, el hecho de mostrar un amplio conocimiento de ella podía permitir al cirujano sumarse a la

61. Offenbach, n. 12, p. 919-920. Nuestra traducción. 
corriente humanista tan en boga entonces. Esto vale, en principio, sólo para aquellos cirujanos cuya formación les permitiera leer y comprender en toda su amplitud el texto de Celso, pero no para los «romancistas»: podría pensarse que estos no pudieron leer el De med., pues no consta traducción a ninguna lengua vernácula. Pero tal visión es del todo errónea: la cantidad de texto celsiano traducido que podía encontrarse en las obras de autores como Fragoso, Díaz o Daza Chacón (y lo mismo valdría para Ambroise Paré en Francia) suponía que prácticamente todos los textos del De med. tocantes a la Cirugía eran accesibles a quien supiera leer el castellano.

Ese importante tratado médico latino concedía, además, amplio y relevante espacio a la parte de la medicina quae manu curat, situándola a un nivel de dignidad equivalente al de la dietética y la farmacia. En él se afirma que médico perfecto es quien domina las tres partes en que se divide su disciplina: y este no era otro que el cirujano, quien, al tiempo que iba logrando la pericia manual, se iba haciendo docto en cuestiones patológicas, anatómicas y farmacológicas, y, por tanto, aproximándose al «arquetipo» del médico mucho más que el físico que no sabía, por ejemplo, sajar correctamente un absceso. "Y todo ello, en gran medida, gracias a y /por el orden/ de Cornelio Celso». 